\title{
Construção do pensamento e das práticas científicas
}

\author{
Ricardo Angelo Monteiro Canale \\ Prof. Licenciado em Matemática - USP \\ ricardo.canale@usp.br
}

\begin{abstract}
Como citar este artigo: Canale, Ricardo Angelo Monteiro. "Construção do pensamento e das práticas científicas". Khronos, Revista de História da Ciência, no 7, pp. 67-80. 2019. Disponível em <http://revistas.usp.br/khronos>. Acesso em $\mathrm{dd} / \mathrm{mm} /$ aaaa.
\end{abstract}

Resumo: Este artigo tem por pretensão analisar a construção e o processo do pensamento e do conhecimento científico e suas práticas na era industrial e pós-industrial. Além disso, o artigo demonstra a relação entre os diferentes grupos científicos e suas práticas (e.g. teórica, experimental ou instrumental) para: i) a troca de objetos de conhecimento e divulgação científica; ii) a formação crítica dos sujeitos; iii) o desenvolvimento do Estado; e iv) a dominação social.

Palavras-chave: Ciência. Pensamento científico. Difusão e divulgação do conhecimento científico. Zonas de troca. Estado e sociedade.

\section{Construction of thought and practices from science}

\begin{abstract}
This article has the intention to analyse the construction and process of thought and scientific knowledge and its practices in the industrial and post-industrial ages. Moreover, it demonstrates the relation between different scientific groups and their practices (e.g. theoretical, experimental or instrumental) to: i) the exchange of objects of knowledge and scientific divulgation; ii) the critical formation of the subjects; iii) the development of State; and iv) the social domination.
\end{abstract}

Keywords: Science. Scientific thought. Diffusion and divulgation of scientific knowledge. Trading zones. State and Society. 


\section{Introdução}

Desde os primórdios da Ciência, o debate sobre a forma do desenvolvimento científico e de se pensar Ciência é intenso. Muito já foi feito a respeito para trazer uma compreensão mais clara de como isso se dá diante da realidade que, conforme Victor Von Stenger ${ }^{1}$, é um dos limites possíveis para a Ciência. Neste ensejo, há uma célebre frase do matemático John Von Neumann, que nos afirma que "As ciências não tentam explicar, elas nem sequer tentam interpretar, elas, principalmente, fazem modelos. Por modelo entende-se uma construção matemática que, com a adição de certas interpretações verbais, descreve fenômenos observados. A justificativa de tal construção matemática é unicamente e precisamente a que se espera que funcione” John Von Neumann apud Stenger, 2007, prefácio, p. 9, tradução livre) $)^{2}$.

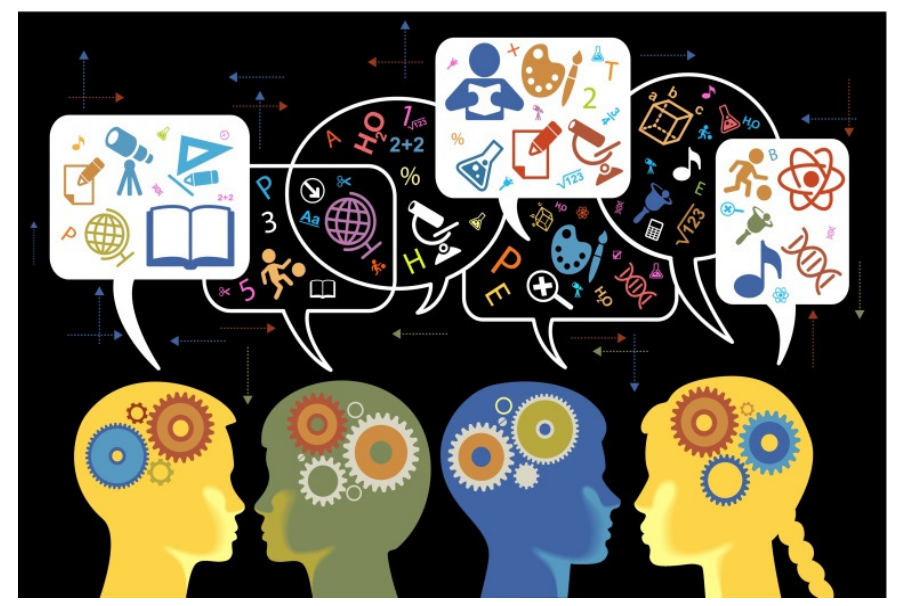

Figura 1 - ilustração do pensamento científico da Istockphoto/thinkstock, reproduzida pelo blog Futurism. Disponível em <https://futurism.com/free-science-the-best-free-courses-and-databases-on-the-internet>. Acessada em 04 mai. 2018.

Culturalmente, costuma-se separar e classificar as coisas em dois grandes blocos, e com a comunidade científica também não é diferente e no final da era industrial surgem duas grandes correntes lógicas de pensamento que influenciaram o pensamento científico e o seu desenvolvimento, a positivista e a antipositivista ${ }^{3}$.

Apesar de serem correntes de pensamento distintas, há um fator em comum entre elas: a ideia de padronizar as Ciências e a sua transformação em etapas e formas pré-estabelecidas

\footnotetext{
1 Vide STENGER, V. J. God: the failed hypothesis - How science shows that God does not exist. 1. ed. Amherst: Prometheus Book, 2007. 294 p.

${ }^{2}$ Retirada originalmente em: STENGER, V. J. Op. cit. p. 9. Original em inglês: "The sciences do not try to explain, they hardly even try to interpret, they mainly make models. By a model is meant a mathematical construct which, with the addition of certain verbal interpretations, describes observed phenomena. The justification of such a mathematical construct is solely and precisely that it is expected to work.". (John Von Neumann apud Stenger, 2007, prefácio, p. 9). ${ }^{3}$ Este ainda é um termo discutido dentro da Filosofia. Há um embate de ideias em torno dos racionalistas e dos pós-modernos sobre a utilização do termo antipositivismo como linha contrária aos paradigmas positivistas.
} 
(como se fossem regras impostas), separando também os diferentes grupos científicos, sejam eles teóricos, experimentais ou mesmo instrumentalistas.

Necessidade de se repensar a forma de se fazer e praticar a ciência: novos modelos

A Ciência - em especial as Factuais ou Experimentais (a exemplo da Física, Química e Biologia) e as Formais (como a Matemática e a Lógica) — não nasceu como algo homogêneo. Ainda é praxe fazer a divisão cultural da Ciência em dois grandes blocos, sendo eles: Naturais e Humanas. Essa desunião dos blocos faz com que a Ciência se desestabilize, gerando lacunas comunicativas e de troca entre as mais diferentes áreas, tendo como consequência a "desregulação" do desenvolvimento científico. Estas concepções vão de encontro com as duas maiores correntes da era pós-industrial, que influenciaram e se firmaram na forma de se fazer ciência: a lógica positivista e a antipositivista (ou "pós-positivismo").

A lógica positivista ou simplesmente positivismo ${ }^{4}$, é considerada a primeira grande proposta contemporânea para base de reflexões filosóficas e científicas. Ela foi concebida por Isidore Auguste Marie François Xavier Comte, e tem por pressuposto a padronização entre as ciências e a constituição de um modelo rígido/imutável de leis e etapas pré-definidas para fazer Ciência, passando das bases observacionais para a teoria, seguido pela experimentação laboratorial e depois para a instrumentação, não deixando espaço para qualquer movimentação entre as etapas, independente da necessidade de momento.

Além disso, o positivismo tenta explicar a necessidade da unidade científica, tendo como direcionamento as bases observacionais. Tais propostas podem gerar um tipo de "freio" ao desenvolvimento científico, pois dificultam a comunicação entre diferentes áreas e práticas científicas, impossibilitando melhores zonas de troca para ampliar o campo de atuação científica e implicando em uma simplificação da teoria para a experimentação e da experimentação para a instrumentação. Alguns filósofos da Ciência, como Thomas Samuel Kuhn, Paul Karl Feyerabend e Peter Lois Galison, mostram que há mudanças e movimentações entre as teorias e as experiências, não havendo ordem correta fixa das coisas, variando conforme a necessidade de análise. Em outras palavras, cada prática ou área da Ciência, seja ela teórica experimental ou instrumentalista, possui características próprias e variam conforme as necessidades e contextos.

Outro grande problema a ser apontado no positivismo é que essa concepção busca suprimir os sentidos da metafísica, exaltando o valor da Ciência como produtora de conhecimento e único guia para a Filosofia e para a vida. Além disso, exclui a Filosofia e a Metafísica como parte da Ciência. Para os adeptos desta linha, não há uma complementação, mas apenas

\footnotetext{
${ }^{4}$ Como curiosidade: o positivismo serviu como fonte para as ideias de formação republicana brasileira, através do militar, engenheiro e político Benjamin Constant Botelho de Magalhães, sendo o lema "Ordem e Progresso", da bandeira brasileira, baseado nesta linha de pensamento.
} 
estágios excludentes. Por exemplo, no primeiro enaltece a explicação divina para a natureza (resultado do conhecimento teológico), o segundo enaltece explicações por ideias abstratas (que são resultados do conhecimento metafísico e filosófico) e no terceiro enaltece a Ciência e a razão como os únicos pilares para a construção de uma sociedade justa, civilizada evoluída. Porém, o problema é que a metafísica é essencial para a Ciência, pois é válido lembrar que os pressupostos científicos são metafísicos e os postulados são filosóficos, ou seja, a base da Ciência é filosófica - na visão positivista, a ideia de uma Filosofia e da metafísica a serviço do conhecimento racional seria excludente.

Já o antipositivismo ou lógica antipositivista - que surge contrariando os paradigmas científicos da lógica positivista - traz o conceito de que a desunião das Ciências causa instabilidade não havendo protocolo fixo entre as linguagens da teoria e do experimento na Ciência. Mas há uma falha dentro do antipositivismo ao reinterpretar a grande valorização das concepções teóricas e rejeitando o empirismo, que é marco da Filosofia da Ciência como disciplina acadêmica de valor filosófico e histórico.

Tanto no positivismo quanto no antipositivismo não se nota a necessidade da interação entre as diferentes áreas e práticas científicas, como demonstram as recentes literaturas científicas, que trazem consigo a ideia das experimentações para além de colher dados e/ou confirmar (ou refutar) alguma teoria. Fazer essas separações ou então enrijecer os sistemas práticos na Ciência torna-se uma forma de refrear o conhecimento científico.

Como exemplos da importância de haver "maleabilidade" entre as diferentes práticas científicas, zonas de trocas e redução dos protocolos de linguagem ${ }^{5}$, temos: I) a descoberta dos elétrons, prótons, nêutrons, e suas ligações eletromagnéticas, onde se fez um esforço considerável entre as áreas da Física de partículas, a Matemática e a Química inorgânica; II) o caso do projeto da Bletchley Park, no Reino Unido, para a quebra do código criptográfico da máquina alemã Enigma durante a II Guerra Mundial, que “obrigou” matemáticos, militares e engenheiros a trabalharem juntos no mesmo local, fazendo a transição entre teorias e práticas; III) a Teoria Quântica de Campos (Equações de Einstein-Maxwell-Dirac) e a utilização da mecânica quântica, que surgiu devido às dificuldades da termodinâmica e do eletromagnetismo em prever corretamente como se fazia a distribuição da frequência em torno da teoria do corpo negro; IV) a teoria dos fractais, em que auxilia na construção de computadores cada vez mais rápidos, através do desenvolvimento da computação quântica e da Matemática; e V) os mapas de Poicaré no desenvolvimento de Sistemas Dinâmicos e da Matemática Discreta. Muitos desses fatos, por sinal,

\footnotetext{
${ }^{5}$ Como observação: isso é algo complexo dentro das Ciências Factuais (ou Experimentais). Por exemplo, o conceito de Energia em Física é diferente do considerado em Química. No primeiro, é a capacidade de transformar força em trabalho. Já no segundo, é a atração das ligações químicas entre os átomos.
} 
eram considerados paradigmas científicos que, após serem quebrados, puderam desenvolver ainda mais a Ciência como um todo.

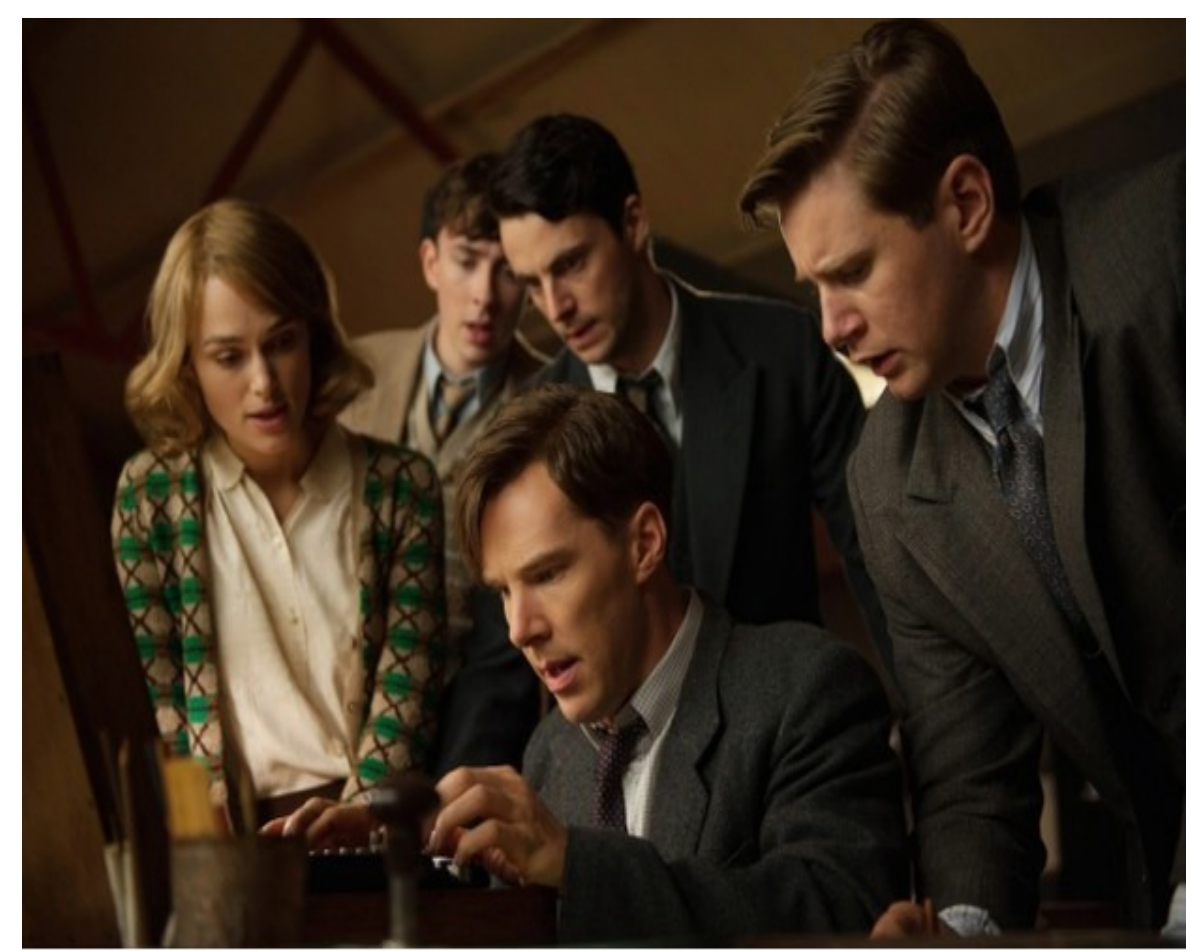

Figura 1 - Reprodução da cena do filme "The Imitation Game" ("O Jogo da Imitação"), de Graham Moore e Morten Tyldum, onde um grupo de cientistas e engenheiros, liderados pelo matemático Alan Mathison Turing, no projeto Bletchley Park, estão trabalhando na decodificação da máquina alemã de criptografia "Enigma". Imagem divulgada pelo sítio eletrônico HistoryExtra, da BBC History Magazine e BBC World Histories Magazine, em notícia publicada em 04 nov. 2014, às 11h17min. Retirada em: <https://www.historyextra.com/period/second-world-war/10-things-you-didnt-know-about-alan-turing-and-bletchley-park/ >. Acessada em: 05 mai. 2018

Ao analisarmos os fatos exibidos até agora, notamos a necessidade de elaborar uma nova maneira de se pensar em Ciência, onde haja maior amplitude e "plasticidade" entre as áreas e que reduza os problemas de linguagem entre elas.

Neste sentido, há uma proposta de Peter Lois Galison ${ }^{6}$ a ser considerada: ele propõe um novo modelo fundamentado nos conceitos de "coordenação local" (conceito desenvolvido por Galison para explicar o que ocorre, em particular, com cada comunidade e práticas científicas), que possibilita a troca de informações e conhecimento entre as diferentes práticas, conforme as necessidades e contextos vigentes. Para isso, Galison explica as diferenças entre as práticas teóricas, experimentais e instrumentalistas, denominando-as como "subculturas" (termo

${ }^{6}$ Vide GALISON, P. Trading zones. Coordinating action and belief. In: BIAGIOLI, M. The Science Studies Reader. 1. ed. London: Routledge, 1990, pp 137-160. Disponível em: <www.ccd.rpi.edu/eglash/sst/galison.pdf>. Acessado em: 28 abr. 2018. 
da antropologia) da sua própria cultura, e as conjecturas que tornam a necessidade de interlocuções e conexões dessas para uma melhor forma de poder conceber o pensamento científico. Galison considera tais conceitos como uma "zona de troca”, e elas ocorrem devido às condições de forças ideológica e local.

Para Galison, um processo "coordenativo local” (conceito desenvolvido por Galison para esmiuçar o que ocorre em particular com cada comunidade e prática científica) se faz por interceptação dessas "zonas de troca”, que possibilitam a interligação e interlocução entre determinados objetos de conhecimento e necessidades. Para tanto, um exemplo trazido por ele é sobre o Rad Lab (Laboratório de Radiação, do Massachusetts Institute of Technology - MIT) - que foi um laboratório privado para estudo e fabricação de radares de micro-ondas (do espectro eletromagnético) e também para elaboração de estratégias de guerra - que, devido às condições da II Guerra Mundial, obrigaram físicos e engenheiros a trabalharem juntos no mesmo local, fazendo transições entre teorias e práticas distintas entre si. A importância do conhecimento científico e a valorização das diferentes práticas científicas como instrumento de desenvolvimento estatal e de dominação.

A importância do conhecimento científico e a valorização das diferentes práticas científicas como instrumento de desenvolvimento estatal e de dominação

$\mathrm{Na}$ era pós-industrial, há diversas formas de se pensar e fazer Ciência. Contudo, como diziam Michel Foucault, Antonio Gramsci e Dominique Pestre, a detenção do conhecimento e sua má utilização, pode servir como forma de dominação de um povo.

O debate sobre o papel social e ético da Ciência e suas práticas com o mundo político - sobretudo com as políticas de Estado e de mercado -, é recorrente desde a introdução das sociedades industriais. Todavia, isso nunca teve um tratamento adequado como ocorre ultimamente. De acordo com Pestre ${ }^{7}$, observa-se que há quatro tendências dominantes sobre prática científica e a política, sendo elas: i) a ciência como sistema de conhecimento e tendências para produção de desenvolvimentos disciplinares e de conceitos; ii) a ciência como sistema de práticas técnicas; iii) a interface científica e a intersecção dela com questões relacionadas com as políticas públicas; e iv) a relação da ciência com o militarismo, especialmente as relacionadas com os contextos das guerras do século XX.

Essas tendências serviram como base nas relações entre os modelos de produção e divulgação científica com os aspectos e interesses políticos envolventes.

7 Vide PESTRE, D. Science, Political Power and the State. In: KRIEGE, J.; PESTRE, D (Eds.). Science in the Twentieth Century. Amsterdam: Harwood Academic Publishers, 1997. pp. 61-65. 


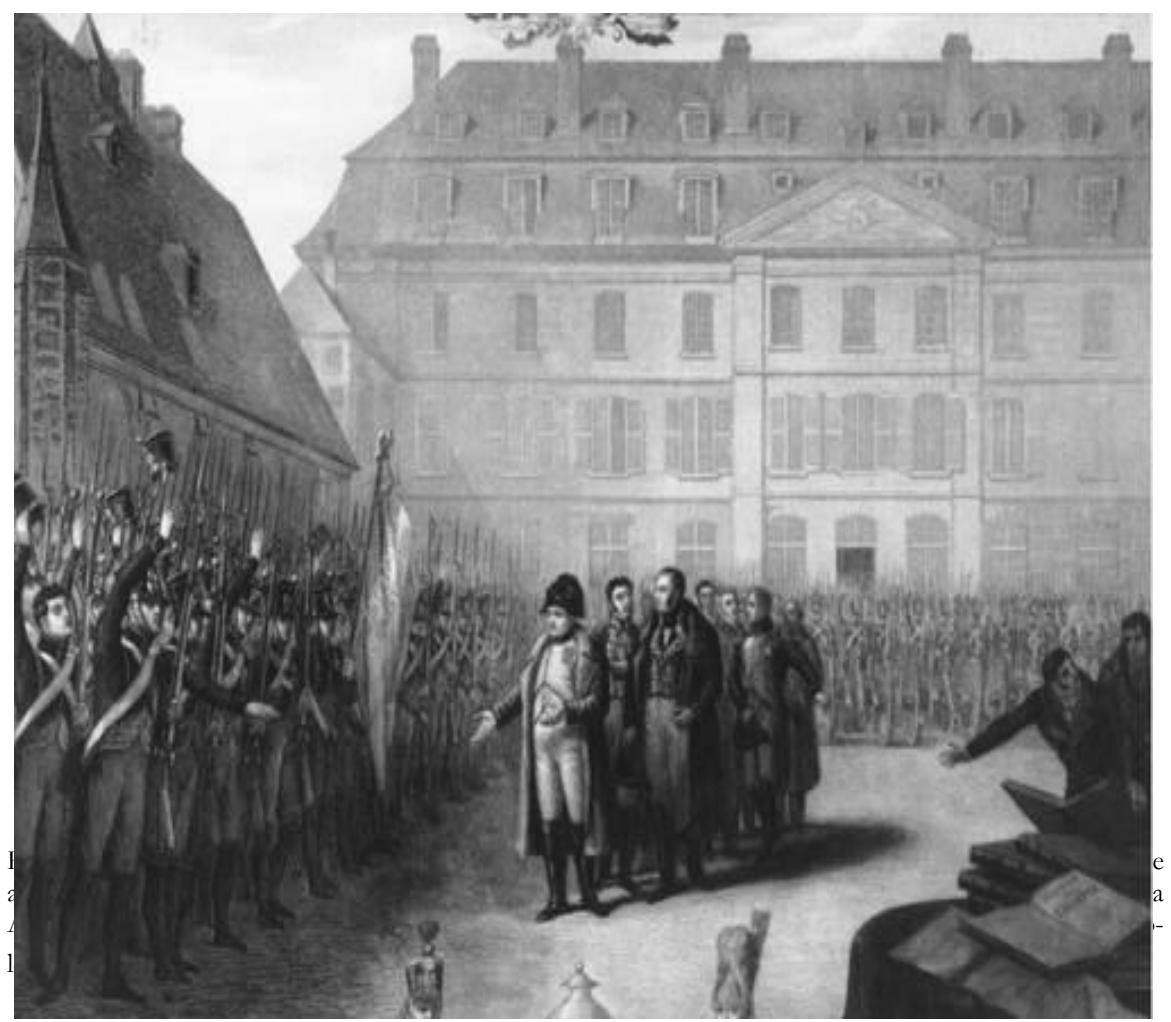

A exemplo do que mostra Pestre, as subordinações das universidades com as políticas de interesse estatais (exemplo dos casos da Ecolè Polytechnique, de Paris, e da Physikalische Technische Reichanstallt, em Berlim, e a importância de suas pesquisas no desenvolvimento de seus respectivos países); a transformação das pesquisas e dos meios de divulgação científica em negócios; a função das ciências dentro das indústrias e do âmbito social (a exemplo da construção da bomba atômica na II Guerra Mundial, o fator reducionista em torno da Biomedicina e o uso da Estatística para análise de dados em benefício da ideologia hegemônica); e as tentativas de retirar a neutralidade da Ciência, que serve como forma de refrear, em parte, o progresso científico.

Conforme se pode observar, o desenvolvimento científico atrelado aos modos de produção tem sua importância na História. Contudo, deve-se ter cautela e uma análise criteriosa das interconexões entre os contextos e objetivos da vida política com as práticas científicas.

No decorrer da história, pôde-se perceber como as interconexões de áreas (em especial o uso de laboratórios especializados) serviram para o desenvolvimento de diversos Estados e nações. 
Neste sentido, pode-se fazer uma análise, por exemplo, sobre o início do período ditatorial do Estado Novo português ${ }^{8}$ e das políticas aplicadas em suas colônias.

De acordo com Tiago Figueiredo Saraiva9 ${ }^{9}$, para que este regime possuísse estabilidade, foram desenvolvidas políticas no setor produtivo agrícola, com a finalidade de converter o território português em uma produtiva máquina tradicionalista que dependesse do cultivo da terra como fonte de toda a virtude nacional, trazendo como exemplo a reformulação da Estação Experimental Agrícola Nacional, do Ministério da Agricultura, colocando-a como um dos principais órgãos para a gerência do Estado, até mesmo mudando sua forma arquitetônica, e dos laboratórios bem como a criação das campanhas nacionais da produção de trigo e tremoço, principais produtos de cultivo e exportação de época.

Nesse período, houve enfoque nos trabalhos dentro dos laboratórios em conjunto com os processos teóricos e instrumentais para criação de novas políticas públicas de Estado, tornando-se eficaz a forma de compreender a paisagem em mudança em Portugal e interagindo com o meio ao redor, na intenção de gerar uma autossuficiência produtiva, permitindo, assim, um controle sobre as terras e também sobre a mão de obra local que, infelizmente, não detinham muito conhecimento técnico de toda a paisagem e seus elementos, dando aos engenheiros e cientistas portugueses e europeus um papel importante no desenvolvimento do Estado e do regime vigente, em Portugal. Ainda conforme Saraiva, tomando-se como exemplo a transcrição gráfica dos territórios coloniais e sua vegetação por meio de laboratórios, amostras e análises instrumentais, e também de especialistas na construção de extensas redes de produção local e do trabalho escravagista - como foram os casos de Moçambique e de São Tomé e Príncipe -, com a função de gerar riqueza à Metrópole, demonstra como as paisagens e as potencialidades de dominação podem ser alteradas dentro dos trabalhos laboratoriais e instrumentais.

Um outro exemplo nesse mesmo sentido é de como as ciências agronômicas - em especial as técnicas de plantio, experiências agronômicas e a botânica - e a constituição de um espaço tropical como um vasto campo investigativo, serviram para um processo de intervenção, disciplinamento e controle das colônias tropicais do Império francês, entre os séculos XIX e XX.

\footnotetext{
${ }^{8}$ Conforme conversas pessoais com a professora Doutora Ana Simões, da Faculdade de Ciências da Universidade de Lisboa (FCUL), Portugal nunca esteve em destaque nas comunidades internacionais científicas. Portugal vem tentando desenvolver trabalhos de qualidade na área, bem assim como de produção historiográfica, com a finalidade de se colocar como um país de centro de desenvolvimento científico e como nação de produção científica de fato, sobretudo na Europa.

${ }^{9}$ SARAIVA, T. Laboratories and Landscapes: The Colonization of Portugal and Mozambique in the Twentieth Century. Journal of History of Science and Technology (HoST), vol. 3, 2009, pp. 7-39. Disponível em: $<$ http://johost.eu/vol3_fall_2009/vol3_ts2.htm z. Acessado em: 05 mai. 2018.
} 
Tais fatos sugestionam como a Ciência se constrói paripassu à economia mundial. Podese notar como os laboratórios serviram como centros de controle dos fenômenos naturais, bem assim como a prática do trabalho disciplinar, da ética e da amostragem de precisão.

Conforme Christophe Bonneuil ${ }^{10}$, a situação colonial nas zonas tropicais impulsionou os cientistas europeus a buscarem novas formas de produção com o objetivo de obter riquezas comercializáveis (e.g. minerais, marfim, cacau, amendoim, borracha e madeira), tendo como base os pressupostos constituídos na revolução agrícola (e.g. rotatividade de cultura em círculos). Para tanto, Bonneuil traz como exemplo a produtividade das colônias francesas do oeste africano, no final do século XIX, que era onde se encontravam as principais fontes de aquisição desses produtos comercializáveis de alto custo, e de como a botânica contribuiu fortemente para uma rica compreensão do clima, da fitogeografia, do potencial agricultável das variadas zonas tropicais e estabelecimento de calendários de agricultura e horticultura, sendo isso um claro elemento essencial para o desenvolvimento da agricultura colônia, da institucionalização das ciências alémmar e da dominação territorial e dos trabalhadores locais.

Segundo Bonneuil, o conhecimento territorial, em especial o do solo, da dinâmica da agricultura local e da modernização induzida dos processos agricultáveis, eram de suma importância para angariar apoio nos programas de colonização e promover também a migração imposta de mão de obra para as áreas de fronteiras agrícolas, tendo como consequência a criação de um câmbio desigual e geração de riquezas ao Império francês em relação às suas colônias. Através disso, Bonneuil nos traz o exemplo do comprometimento da coleta dos nomes das novas descobertas exploratórias por meio dos grupos viajantes que tinham, interligados às novas instalações, função de incorporar o conhecimento nativo, as atividades comerciais e a ciência botânica a um quadro abrangente de influência local e global, como ocorreu com a produção de amendoim em Senegal e da borracha na Indochina francesa ${ }^{11}$, especialmente na região que hoje corresponde ao Vietnã.

A partir do que foi elucidado a respeito dos estudos e análises de Saraiva e Bonneuil, observa-se o papel do conhecimento científico e das práticas e objetos laboratoriais experimentais como uma forma de dominação e de ajustes de processos de intervenção, disciplinamento e controle em relação à propensão administrativa direta das Metrópoles às suas colônias, dependendo de seus objetivos e da maneira como eles são postos em prática.

10 Vide BONNEUIL, C. Crafting and Disciplining the Tropics: Plant science in the French colonies. In: KRIEGE, J.; PESTRE, D (Eds.). Science in the Twentieth Century. Amsterdam: Harwood Academic Publishers, 1997. pp. 77-96.

${ }^{11}$ Região da Península Indochinesa, no sudeste asiático, colonizada pelos franceses até meados do século XIX e começo do século XX. Atualmente, essa região é compreendida por Vietnã, Laos e Camboja. 
Até aqui, pôde-se perceber que, conforme se faz e pensa Ciência, pode servir tanto como um meio de avanço, superação de paradigmas e libertação de conhecimento quanto como forma de dominação e controle de um povo.

A partir disso, pode-se também falar a respeito do papel da divulgação científica nos meios populares, tendo sob óptica a influência da ideologia hegemônica e da falta de incentivo à alfabetização científica de maneira pedagógica, popular e libertadora.

Um dos pressupostos da divulgação científica é a popularização da Ciência e a geração de pensamento crítico. É com apoio da divulgação científica que se chama a atenção para o que de fato seria a Ciência, suas raízes, práticas e como ela se dá. Isto é, a divulgação científica tem potencial de objeto-ferramenta na alfabetização e letramento científico, auxiliando na potencialidade do raciocínio lógico-dedutivo, na leitura e interpretação de texto e também na formação crítica do sujeito. Raramente as divulgações científicas são promovidas de maneira pública, popular e fácil, com documentários em linguagem simplificada, compêndios e noticiários massivos ou mesmo colóquios e seminários que consigam ao mesmo tempo abordar conteúdos complexos e trazer consigo leigos e entusiastas que estejam por fora das especificidades de tais conteúdos. Mais raro ainda se faz presente as conceituações fenomenológicas das ciências de forma geral. Muitas vezes se observa apenas algo atrelado diretamente às divulgações para grupos especializados ou de uma elite letrada, mesmo com os avanços que se tem obtido com os meios de comunicação de massa. Ou então, quando divulgado de maneira popular, como o caso da descoberta do Bóson de Higgs (rotulado erroneamente de "partícula de Deus"), há a aplicação não adequada de termos e conceitos devido à dificuldade da alfabetização científica popular e também da participação ativa de revisão científica dentro dos meios de comunicação de massas. 


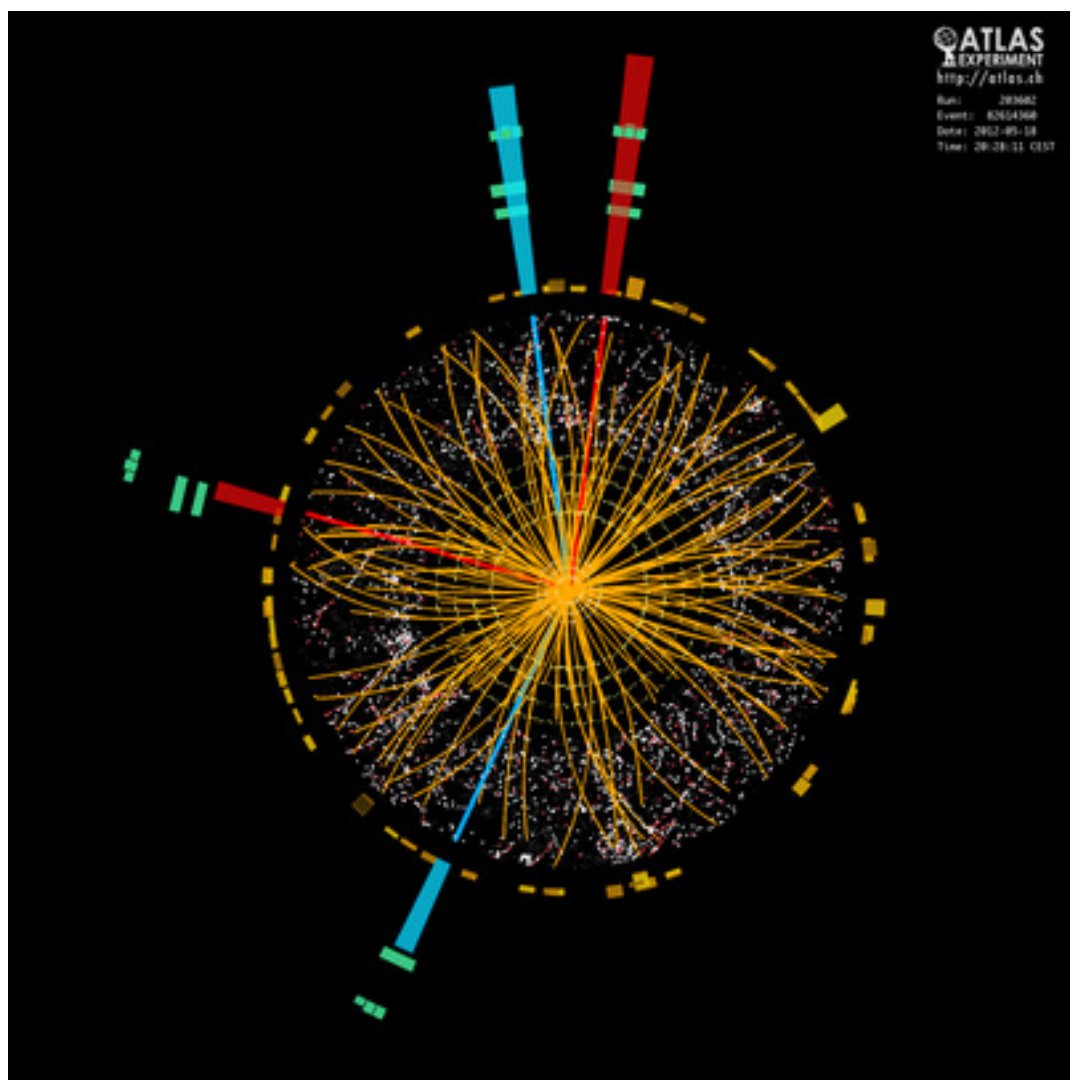

Figura 3 - Fotografia do Bóson de Higgs, colbida através do teste ATL AS, no Grande Colisor de Hádrons, divulgada pela Organização Europeia para a Pesquisa Nuclear (antigo Conselho Europeu de Pesquisa Nuclear - CERN), reproduzida pela Revista Galileu, do grupo Globo, em notícia de 02 set. 2015, às 16h09min, com atualização da reportagem feita às 16 b09min09s, pelo repórter André Jorge de Oliveira. Retirada em: <https://revistagalileu.globo.com/Ciencia/noticia/2015/09/ boson-de-higgs-divulgada-foto-mais-nitida-da-particula.html>. Acessada em: 06 mai. 2018.

De maneira geral, o que se tem costume de divulgar sobre ciência nos meios de comunicação de massa são as maiores tendências para ganho de adeptos, a exemplo de coisas práticas no dia a dia, ficção científica ou sobre algum fato que diz respeito aos astros. A exemplo disso pode-se citar o fenômeno de conjunção planetária Vênus-Júpiter, ocorrido em 30 de junho de 2015, que é um fenômeno raro, em que não houve quase nenhuma divulgação nos meios de comunicação de maior impacto. Outro exemplo neste sentido é sobre a erradicação total da transmissão vertical do HIV (Human Immunodeficiency Virus) ${ }^{12}$ em Cuba, no ano de 2015, conforme dados oficiais da Organização Mundial da Saúde $(\mathrm{OMS})^{13}$ e da Organização Panamericana da Saúde (OPS) ${ }^{14}$, que, devido ao boicote político e econômico à Ilha, houve pouca divulgação do fato. Ao invés disso, no que diz respeito à mídia brasileira, dá-se maior respaldo ao que envolve pequenos fatores práticos para o bem-estar, como parte de estética e de pequenos cuidados

12 Vírus da Imunodeficiência Humana (VIH), em português.

13 Vide AYUSO, S. Cuba é o primeiro país a eliminar a transmissão do HIV de mãe para filho: OMS diz que ilha conseguiu feito inédito de erradicar a transmissão do vírus e da sífilis. El País, Saúde, 30 jun. 2015. Disponível em: <https://brasil.elpais.com/brasil/2015/06/30/ciencia/1435677308_417885.html>. Acessada em: 05 mai. 2018.

${ }^{14}$ Ibidem. 
na saúde pessoal, a exemplo do fato de se lavarem as mãos ou então sobre algum produto inovador no mercado para peles ressecadas.

Nos casos exemplificados anteriormente, com relação à mídia brasileira, foram melhores divulgados em meios muito específicos da área ou então em blogs e sítios eletrônicos independentes ou através de órgãos governamentais envolvidos com os temas, como, por exemplo, o Ministério da Saúde (MS) e o Ministério de Ciência, Tecnologia e Inovação (MCTI), hoje, Ministério de Ciência, Tecnologia e Inovação e Comunicações (MCTIC). Um outro exemplo neste sentido é o caso do ingresso do Brasil na elite da Matemática mundial ${ }^{15}$, por meio de sua inserção no Grupo 5, da International Mathematical Union ${ }^{16}$ (IMU), através de um trabalho primoroso em conjunto feito pelo Instituto de Matemática Pura e Aplicada (IMPA) e a Sociedade Brasileira de Matemática (SBM), que ainda teve uma divulgação escassa nas mídias comunicativas de massa, mas que foi mais adequadamente noticiado pelos órgãos oficiais, incluindo o próprio IMPA e a SBM.

Atualmente, o Brasil tem tido uma série de dificuldades com relação à promoção da educação científica e de sua divulgação. Isso ocorre por uma série de fatores, sendo eles: falta de incentivo financeiro, falhas na linguagem de comunicação, político, fundamentalismo teocrático, sensacionalismo midiático, entre outros. Tem-se visto ainda problemas em campanhas básicas sanitaristas e disseminação de notícias falsas entre pessoas em meios de comunicação e de troca de informações populares que, sem um preparo adequado dos órgãos públicos e também de uma divulgação científica ampla e coerente, tem permitido retrocessos no país que tem custado a vida de pessoas, como, por exemplo, o aumento de doenças graves como poliomielite, difteria e rubéola, que haviam sido erradicadas há mais de 20 anos no país ${ }^{17}$. Ou seja, por dificuldades como as supracitadas, demonstra-se uma certa urgência da implementação de melhorias e ampliação dos meios de divulgação e difusão científica. Além disso, faz-se válido ressaltar que tais ações populares se fazem também como questionamentos do papel do cientista na sociedade e do próprio valor do conhecimento científico, tendo ainda a dificuldade de encontrá-los como práticas sociais e exercícios da dialética social e de incursão social à natureza do saber científico.

15 Pode ser conferido em: IMPA. Brasil é promovido à elite da matemática mundial. IMPA, 25 jan. 2018. Disponível em: <https://impa.br/page-noticias/brasil-e-promovido-a-elite-da-matematica-mundial/>. Acessada em: 10 jul. 2018.

${ }^{16}$ União Matemática Internacional, em português.

17 Vide MODELLI, L. Sarampo, pólio, difteria e rubéola voltam a ameaçar após erradicação no Brasil: O sarampo era considerado uma doença erradicada no Brasil desde 2016, quando a Organização Mundial da Saúde (OMS) identificou que o país estava havia um ano sem registro de casos do vírus. Mas isso mudou neste ano: boletins recentes da entidade advertem que está em curso um surto da doença, altamente contagiosa e que pode levar à morte de crianças pequenas ou causar sequelas graves. BBC News Brasil, 7 jul. 2018. Disponível em: <https://www.bbc.com/portuguese/brasil-44706026>. Acessada em: 08 jul. 2018. 
Considerações finais e "novos" rumos para a ciência: retomada ao gosto do saber pelo saber

No decorrer da história da Ciência, observa-se que a Ciência tem um importante papel para o desenvolvimento e aprendizado da Humanidade.

A partir do que foi exposto, podemos concluir ser necessário repensar o desenvolvimento científico e a comunicação entre as ciências, tendo um olhar ao progresso da humanidade. Além disso, observa-se que ainda há uma necessidade constante na luta pela manutenção da neutralidade científica e também da independência das pesquisas, tendo por finalidade o progresso intelectual, a liberdade dos indivíduos, o avanço social e a manutenção da soberania nacional. Para tanto, devem ser implementados trabalhos na área de alfabetização científica desde tenra idade escolar, com a finalidade de promover o saber crítico e possibilitar observar que a Ciência não é apenas um amontoado de ideias jogadas ao vento ou simplesmente descobertas de mentes mirabolantes. Essa alfabetização científica precisa ter como viés a formação crítica do sujeito e que traga à tona a natureza das ciências como um processo de construção factível e de investigação. Para que isso ocorra de forma adequada, conforme Borges ${ }^{18}$, precisa-se dar atenção ados limites e possibilidades das atividades práticas no ensino-aprendizagem de Ciência e na formação do sujeito, em especial sobre os papéis dos laboratórios escolares de ciências nas aulas de ciências, dos laboratórios tradicionais e do uso dos computadores como recurso metodológico facilitador e de apoio à simulação, coleta e análise de dados, e também à discussão de resultados. Para Borges, os roteiros dos exercícios de laboratório não devem focar apenas em problemas fechados (i.e. que envolve situações-problema e maior autonomia estudantil durante o processo) ou mesmo virem prontos, pois isso leva somente aos estudos da instrumentação laboratorial e ainda pode ocorrer uma tendência à manipulação de dados obtidos para ficar à par das expectativas teóricas, já que costumeiramente os estudantes possuem medo de errar, ainda mais quando acarreta alguma incompatibilidade com a expectativa teórica. Isso faz com que empobreça as discussões de resultados e muitas vezes deixa de se observar e discutir os fenômenos que levaram àqueles dados em específico. De acordo com Borges, o que acarreta tais empecilhos citados anteriormente são as dificuldades de um planejamento adequado de ensino, de aulas, das práticas laboratoriais e seus objetivos, da confusão sobre as práticas laboratoriais pedagógicas escolares com as práticas laboratoriais dos cientistas, da administração de tempo, da consideração dos saberes e vicissitudes estudantis e até mesmo da formação docente. Com isso, o ensino tradicional de práticas laboratoriais escolar necessita passar por um processo de revisão e de reformulação, já que os elementos supracitados têm demonstrado certo grau de ineficiência no ensino e aprendizagem de Ciências por parte desta modalidade e metodologia de ensino-aprendizagem. Conforme Borges, o trabalho no laboratório pode ser organizado de diversas maneiras, desde demonstrações até atividades prático-experimentais dirigidas diretamente pelo professor

18 Vide BORGES, A.T. Novos rumos para o laboratório escolar de Ciências. Caderno Brasileiro de Ensino de Física, v. 9, n. 3, pp. 291-313, 2002. 
ou indiretamente, através de um roteiro que valorize uma metodologia didático-pedagógica investigativa tanto de problemas fechados quanto abertos (i.e. que envolve situações-problemas reflexivos e de maior autonomia estudantil durante o processo) e que permita discussões sobre dados colhidos e conclusões tomadas durante todo o processo. Dentro deste espectro, Borges nos sugestiona uma formação de professores que possibilite a compreensão da natureza da Ciência e dos seus pressupostos investigativos, trazendo à tona os diversos métodos científicos aos seus alunos. Nesse sentido Borges nos diz que “[...] é urgente que livros-texto e os cursos de formação de professores nos vários níveis passem a se preocupar mais com as imagens sobre a natureza da ciência que, implícita ou explicitamente, transmitem aos docentes e estudante de ciências" (BORGES, 2002, p. 311) ${ }^{19}$.

Observou-se no decorrer do texto que, para que haja uma alfabetização e letramento científicos adequados, deve-se contar com o apoio de uma divulgação científica e transposição de conhecimento de forma concisa nas mídias de massa, pois isso pode trazer bons frutos ao desenvolvimento social e pessoal, servindo como meio de libertação e união dos indivíduos.

Para tanto, nota-se que também é preciso reformular as concepções das práticas científicas quanto às suas finalidades, amplitudes, "plasticidade" e maleabilidade. Essas práticas não podem estar intrinsicamente vinculadas ao modo de produção vigente e tampouco como apenas um produto social, pois, caso contrário, poderão produzir brechas para dominação e fortalecimento de regimes de déspotas, como foi durante o is construtores da história pública no mundo.

\footnotetext{
${ }^{19}$ Retirada originalmente em BORGES, A.T. Op. cit. p. 311.
} 